EM

\title{
A REFORMA AGRÁRIA DE MERCADO E O (SUB)DESENVOLVIMENTO RURAL: A EXPERIÊNCIA DO ASSENTAMENTO DA FAZENDA PAZ (MAXARANGUAPE/RN)
}

\section{THE AGRARIAN MARKET REFORM AND THE (SUB)RURAL DEVELOPMENT: THE EXPERIENCE OF THE SUBSIDENCE OF FAZENDA PAZ (MAXARANGUAPE/RN)}

\author{
Vinícius Rodrigues Vieira FERNANDES ${ }^{1}$ \\ João MATOS FILHO ${ }^{2}$
}

\begin{abstract}
Resumo: Analisa-se a trajetória dos assentamentos financiados pela Reforma Agrária de Mercado, buscando-se compreender quais os fatores que promovem ou limitam o processo de desenvolvimento rural desses assentamentos. Toma-se como referência a experiência do Assentamento da Fazenda Paz, no município de Maxaranguape/RN. Para o estudo deste caso, fez-se uso de visitas ao Assentamento e entrevistas semiestruturadas com agentes que participaram ativamente do projeto. Os resultados evidenciam um período de sucesso, que pode ser creditado à integração de políticas públicas e a existência de diversificação, empreendedorismo, pluriatividade e capital social no Assentamento, e outro de fracasso, que pode ser explicado pelo modelo de agricultura empreendido, existência de dificuldades relacionadas à gestão, à quebra de confiança entre os assentados e ao distanciamento das organizações governamentais. Conclui-se, que é preciso repensar o desenvolvimento rural como um fenômeno multidimensional, pautado na interação entre boas políticas e um ambiente institucional favorável e que demanda um amplo envolvimento entre Estado e sociedade sob as bases de um contrato territorial de desenvolvimento.
\end{abstract}

Palavras-chave: Desenvolvimento rural; Reforma Agrária de Mercado; Assentamento da Fazenda Paz.

\begin{abstract}
The trajectory of subsidences financed by the Agrarian Market Reform is analyzed, seeking to understand which factors promote or limit the process of rural development in these subsidences. The experience of the Subsidence of Fazenda Paz, in the municipality of Maxaranguape/RN (Brazil), is used as a reference. For the study of this case, visits to the subsidence and semi-structured interviews with agents who actively participated in the project were used. The results show a period of success, which can be credited to the integration of public policies and the existence of diversification, entrepreneurship, pluriactivity and social capital in the subsidence, and another of failure, which can be explained by the model of agriculture undertaken, existence of difficulties related to management, the breach of trust between the settlers and the distance from government organizations. It is concluded that it is necessary to rethink rural development as a multidimensional phenomenon, based on the interaction between good policies and a favorable institutional environment and that demands a broad involvement between State and society under the bases of a territorial development contract.
\end{abstract}

Keywords: Rural development; Agrarian Market Reform; Subsidence of Fazenda Paz.

\footnotetext{
${ }^{1}$ Doutor em Economia pela Universidade Federal de Uberlândia (UFU). Professor Adjunto do Departamento de Economia da Universidade Federal de Roraima (UFRR). E-mail: vinirvf@gmail.com.

2 Doutor em Economia pela Universidade Estadual de Campinas (UNICAMP). Professor Titular do Departamento de Economia da Universidade Federal do Rio Grande do Norte (UFRN). matosfilho@ gmail.com
} 
EM

\section{Introdução}

O papel da agricultura e da reforma agrária no desenvolvimento econômico tem se mostrado recorrente na agenda das políticas públicas para o meio rural brasileiro, sobretudo a partir dos anos 1950, quando o debate teórico colocou em polos opostos aqueles que defendiam e aqueles que negavam a imprescindibilidade da reforma agrária para garantir o abastecimento alimentar dos centros urbano-industriais que cresciam sob a égide do desenvolvimentismo e da industrialização por substituição de importações.

O tema da reforma agrária perdeu prioridade durante todo o período do regime militar, sendo retomado somente no final dos anos 1980, com o processo de redemocratização do país, o protagonismo dos movimentos sociais e os efeitos negativos da modernização conservadora. Esse processo é acompanhado pela institucionalização de um modelo alternativo de distribuição de terras, isto é, além da tradicional via de desapropriação por interesse social. Trata-se da Reforma Agrária de Mercado (RAM), recomendada e financiada pelo Banco Mundial, que visa estabelecer uma relação mercantil entre compradores e vendedores de terras.

É sobre esta via alternativa de reforma agrária que trata este trabalho. Diante disto, o presente artigo procura contribuir para um conhecimento mais aprofundado dos meandros e das especificidades da gestão dos assentamentos financiados pela RAM, por meio do estudo de caso do Assentamento da Fazenda Paz. Localizada em Maxaranguape, no Rio Grande do Norte, a Fazenda Paz foi adquirida em 2007 por 80 famílias, via recursos do Programa Nacional do Crédito Fundiário (PNCF). Entre os anos de 2007 e 2011, o projeto apresentou importantes resultados, sucesso este interrompido no ano de 2012, quando os assentados procuraram diversas instituições para que ajudassem a salvar o projeto.

Nesse contexto, uma pergunta central de pesquisa emerge: quais os fatores que promoveram o êxito e a descontinuidade do processo de desenvolvimento rural do Assentamento da Fazenda Paz? O objetivo geral deste trabalho é analisar as potencialidades e os limites presentes na trajetória do Assentamento da Fazenda Paz.

Para tanto, optou-se pela realização de entrevistas semiestruturadas com atores que participaram ativamente desde o processo de formação da Associação da Cooperativa da Agricultura Familiar da Fazenda Paz (ACAPAZ) e da Cooperativa dos Agricultores dos Frutos da Paz (COOAPAZ), passando pela fase de sucesso até o seu período de descontinuidade. Ao todo, foram realizadas oito entrevistas, com dez pessoas diferentes, divididas da seguinte forma: (i) o presidente da COOAPAZ; (ii) um assentado da Fazenda 
EM

QUESTÃO

V.14 N. $02 \bullet 2021$

pág. 232-261

Paz; (iii) uma assentada da Fazenda Paz; (iv) duas representantes da atual diretoria da ACAPAZ; (v) dois representantes da Federação dos Trabalhadores na Agricultura Rio Grande do Norte (FETARN); (vi) um membro do Ministério do Desenvolvimento Agrário (MDA); (vii) um representante da Instituto de Assistência Técnica e Extensão Rural do Rio Grande do Norte (EMATER/RN); e (viii) um membro da Organização de Aprendizagem e Saberes em Iniciativas Solidárias do Rio Grande do Norte (OASIS/RN).

Além desta introdução, o estudo possui outros seis itens. No segundo, abordam-se algumas das mais recentes abordagens que tratam do desenvolvimento rural. Em um terceiro momento, aproxima-se este contexto com a discussão do modelo de RAM. No item 4, apresenta-se, de forma geral, o Assentamento da Fazenda Paz. O item 5 traz a análise dos resultados, especificamente a que diz respeito aos fatores exitosos do projeto. No item 6 , analisam-se os problemas enfrentados pelo Assentamento da Fazenda Paz que culminaram na sua descontinuidade. Por fim, têm-se as principais reflexões do estudo e orientações para possíveis políticas públicas.

\section{Recentes abordagens teóricas sobre desenvolvimento rural}

A partir das décadas de 1980 e 1990, além da retomada da discussão sobre a reforma agrária, a temática do desenvolvimento rural volta à agenda governamental, adquirindo um maior espaço no âmbito político e acadêmico. Nesse contexto, muitos estudiosos passaram a investigar os principais aspectos do desenvolvimento rural no Brasil, formulando assim estratégias que servem de orientação para possíveis políticas públicas de combate à pobreza rural e melhorias das condições de vida dos agricultores familiares.

Dentre as diversas abordagens do desenvolvimento rural encontradas na literatura especializada, procurou-se selecionar aquelas que fundamentassem os discursos dos atores entrevistados. Feito esta ressalva, adverte-se que a análise do estudo recairá, a seguir, em cinco vertentes principais, priorizando autores específicos, sendo as três primeiras relacionadas ao período de êxito do Assentamento da Fazenda Paz e as duas últimas relacionadas ao período de descontinuidade do projeto. 
EM

QUESTÃO

$\mathrm{O}$ foco na agricultura familiar

A agricultura familiar, isto é, aquela dirigida pelo próprio produtor rural e que utiliza prioritariamente a mão de obra familiar frente ao trabalhador contratado, permeia os estudos de José Eli da Veiga. Nesse contexto, o autor (1998) desmistifica a centralização na agricultura patronal como premissa para o desenvolvimento. Utilizando-se de argumentos baseados nas experiências internacionais, mostra que a agricultura familiar seria o sistema mais equitativo e sustentável no meio rural brasileiro.

Assim como nos países capitalistas avançados, a estratégia básica para o desenvolvimento rural passaria, então, pelo fortalecimento da agricultura familiar, seja por políticas de crédito, políticas de reforma agrária, desenvolvimento de pesquisas agropecuárias, criação de uma infraestrutura básica para a produção da agricultura familiar e a existência de uma assistência técnica especializada.

Em outro estudo, Veiga (2001) chama atenção para a diversificação produtiva como fonte geradora de divisas na agricultura familiar, de modo que uma agricultura com mobilidade de recursos e força de trabalho, associada a um sistema de redes de pequenas e médias empresas, eleva a probabilidade de desenvolvimento local, acarretando no progresso das áreas rurais. Sendo assim, a diversificação permite o surgimento de uma trindade econômica, composta pelas economias de escala, economias de escopo e custos de transação, acarretando externalidades positivas face às culturas especializadas em um único tipo de produção.

Em paralelo com essa visão, o empreendedorismo e a existência de clusters ganham notoriedade nos estudos do autor. Os agentes empreendedores seriam os principais responsáveis pela mudança econômica, tendo em vista que buscam e disseminam novas tecnologias. De maneira paralela, as concentrações espaciais são vitais para a difusão de conhecimentos, experiências e modos de produção.

Na perspectiva de Veiga et al. (2001), a intervenção do Estado, nesse processo, não deve se limitar a uma simples transferência de recursos. Trata-se, em última instância, de uma parceria entre governo e sociedade no âmbito do diagnóstico de problemas locais, planejamento de ações e captação de recursos para a execução dos planos de desenvolvimento.

De acordo com a denominação dada pelos autores, seria uma espécie de Contrato Territorial de Desenvolvimento (CTD), com delimitações definidas sobre compromissos e responsabilidades da parceria entre os atores sociais e o Estado, abrangendo três diretrizes: (i) 
EM

QUESTÃO

V.14 N. $02 \bullet 2021$

pág. 232-261

aquisição de competência (apoio técnico à captação de recursos, diagnóstico do território, apoio técnico à elaboração do plano de desenvolvimento, sensibilização da população); (ii) inovação rural (envolvendo um grande suporte educacional, transferência e difusão de tecnologias, apoio em pesquisa e desenvolvimento voltado ao setor agropecuário); e (iii) criação de redes (formação de uma rede de solidariedade e cooperação nas regiões rurais, promovendo o intercâmbio de conhecimentos e experiências).

De posse do que foi apresentado, Veiga et al. (2001) apresentam duas alternativas estratégicas para o campo: (i) fortalecer o agribusiness, o que tende a gerar uma redução dos postos de trabalho na agricultura vis-à-vis aumento do êxodo rural, elevação do número de desempregados em outros setores da economia e crescimento das desigualdades sociais; ou (ii) maximizar as oportunidades de desenvolvimento humano nas regiões rurais, favorecendo a industrialização difusa e a descentralização dos serviços, além de distribuir o nível de emprego de forma mais equitativa entre os setores, desafogando as aglomerações urbanas.

A pluriatividade na agricultura familiar

Outra recente abordagem teórica sobre desenvolvimento rural reside na ideia da pluriatividade, que ganha importância com os trabalhos de Sérgio Schneider. Na concepção do autor, a pluriatividade é:

Um fenômeno através do qual membros das famílias de agricultores que habitam no meio rural optam pelo exercício de diferentes atividades, ou mais rigorosamente, optam pelo exercício de atividades não-agrícolas, mantendo a moradia no campo e uma ligação, inclusive produtiva, com a agricultura e a vida no espaço rural (SCHNEIDER, 2009, p. 97).

Longe de servir apenas como uma forma alternativa de subsistência, a pluriatividade é, portanto, uma estratégia para a reprodução das famílias, configurando um processo permanente no espaço rural. Na visão do autor (2009), a pluriatividade compreende um dinâmica intrínseca à própria família. Ora, é a capacidade de alguns membros da família de se relacionarem com um ambiente institucional, econômico e social que torna os agricultores pluriativos. São vínculos, intercâmbios, novas relações sociais com o meio urbano e inserções na nova divisão do trabalho que compõem o aspecto da pluriatividade e que agem como uma estratégia para a reprodução social da família.

Partindo das mudanças provocadas pela globalização no meio rural e buscando propor estratégias para o desenvolvimento rural, Schneider (2005), citado por Souza, R. e 
Souza, M. (2008), tece algumas políticas públicas: (i) combinar instrumentos de estímulo às atividades agrícolas e outros mecanismos que fortaleçam e expandam as atividades nãoagrícolas; (ii) investigar quais instrumentos seriam os mais adequados para estimular um ambiente social e econômico favorável ao aparecimento da pluriatividade; (iii) promover a conciliação entre os diferentes níveis de governo (local, estadual e federal) para que não ocorra sobreposição e que a ação de uma esfera não gere impedimentos a atuação da outra; (iv) diferenciar as iniciativas de geração da pluriatividade, segundo as características locais e regionais, o que implica em instrumentos e ações diferenciadas; e (v) criação de infraestrutura (estradas, meio de comunicação) para auxiliar no desenvolvimento de atividades nãoagrícolas.

O enfoque territorial do desenvolvimento rural

O modo de produção/acumulação Fordista, baseado em grandes plantas industriais, reunião de um imenso contingente de trabalhadores operando sob um regime altamente hierarquizado e centralizado por parte de autoridade industrial, ditava o ritmo das políticas até o período posterior à Segunda Guerra Mundial (ABRAMOVAY; BEDUSCHI FILHO, 2004). Entretanto, a rigidez do modelo e a intensa organização do trabalho fizeram com que modos de produção mais flexíveis adquirissem evidência, com destaque para a importância do trabalhador multifuncional, capaz de reduzir custos e possibilitar a diferenciação do produto. Nesse enfoque, a interação, cooperação e a troca de experiências poderiam gerar ganhos significativos para as empresas.

Mas, em qual ambiente essas relações sociais de produção seriam transmitidas? No território. Na concepção de Abramovay (2000), os territórios estão longe de compreenderem simples definições locacionais ou delimitações geográficas nas quais os atores sociais atuam. A visão de território é bem mais complexa, abrange as relações informais entre os indivíduos, acopla as raízes históricas de uma determinada sociedade, ou seja, uma verdadeira representação física das identidades culturais, sociais, políticas e econômicas de uma sociedade. Além disso, e de caráter não menos importante, a difusão do conhecimento, a interação entre os agentes privados e a cooperação ganham vida nos territórios.

Por sua vez, em um cenário composto pelas relações sociais entre os indivíduos, propaga-se a ideia do capital social, que compreende o conjunto das características da organização social, como confiança, normas e sistemas, que contribuem para aumentar a eficiência da sociedade, facilitando as ações coordenadas (PUTNAM, 1996). Seguindo esta 
matriz de conhecimento, Abramovay (2000) destaca a capacidade, por parte dos atores sociais, de estabelecer relações organizadas, de caráter mercantil ou não, favorecendo a troca de informações e a inserção em novos mercados, como também de bens públicos e de administração com a meta de dinamizar a vida regional, potencializando capital social onde até então não existia.

O enfoque territorial ganha relevância com a ideia dos novos distritos industriais marshallianos, na Terceira Itália. Nesse sentido, Abramovay (2000) cita três laços básicos que permitiram o desenvolvimento territorial dessas regiões, a saber: (i) existência de um conjunto diversificado e com alto grau de interação das empresas familiares; (ii) a presença de um ambiente propício ao surgimento de inovações e trocas de informações entre indivíduos e empresas, no qual a cooperação é tão importante quanto a cooperação; e (iii) integração entre indivíduos urbanos e rurais.

Adentrando ainda mais no cerne da questão deste trabalho, Abramovay e Beduschi Filho (2004) procuraram apresentar propostas que objetivassem mudanças estruturais com um enfoque territorial. Inicialmente, os autores relatam a necessidade de uma maior canalização dos recursos voltados às localidades com o objetivo de fomentar a elaboração de planos de desenvolvimento inovadores.

Para a efetiva capacitação da sociedade na elaboração desses projetos, deve-se construir uma política de apoio aos institutos de pesquisa, faculdades e universidades do país, isto é, fomentar a educação é o primeiro passo para o desenvolvimento do empreendedorismo individual e coletivo. Além disso, os autores defendem o estímulo à formação de cooperativas de crédito e agências locais de crédito capazes de reduzir a assimetria de informações entre as iniciativas locais e o sistema financeiro convencional.

O modo camponês de fazer agricultura

O desenvolvimento rural é um processo que envolve uma luta diária do agricultor familiar em buscar e promover sua autonomia política, econômica e social. Para um maior entendimento dessas questões, pode-se recorrer aos aportes teóricos de Ploeg (2008), sobretudo na sua análise em relação às agriculturas camponesa e empresarial.

De acordo com o autor, o modo camponês de fazer agricultura é pautado: (i) na coprodução entre o homem e a natureza viva; (ii) na produção e crescimento do máximo de valor agregado possível, utilizando, principalmente, recursos autocriados e auto manejados; (iii) na operacionalização dentro de certos limites estruturais, em especial, em um contexto de 
EM

QUESTÃO

V.14 N. $02 \bullet 2021$

pág. 232-261

baixa oferta de recursos disponíveis por unidade de produção e consumo; (iv) na intensa utilização de mão de obra comparativamente ao uso da terra e dos animais; (iv) no controle da unidade orgânica dos recursos sociais e materiais; (v) na potencialização do fator trabalho; e (vi) nas relações diferenciadas com os mercados, que são baseadas em recursos produzidos e reproduzidos, destinando uma parte das mercadorias para o mercado e outra para a reprodução da unidade de produção.

$\mathrm{Na}$ contramão da agricultura camponesa, o autor destaca que a agricultura empresarial ancora-se fortemente na dependência externa, no distanciamento da natureza e dos ecossistemas, na preferência por elementos artificiais e industriais, na escala de produção e no seu aumento (mediante a intensificação do uso de tecnologias via financiamento de crédito do sistema bancário, reforçando o processo de dependência), especialização e na constante ruptura, fundamentalmente tecnológica e de processo, sob a égide da "destruição criadora" schumpeteriana, na qual o novo sobrepõe o velho numa transição tipicamente capitalista.

Em última instância, o autor ressalta que o modo empresarial de fazer agricultura necessita de certas condições para se reproduzir, tais como a estabilidade dos preços pagos aos produtores com uma efetiva margem de lucro, estabilidade do mercado quanto aos custos, taxas de juros, intervenção estatal em tempos de crise e plenas garantias da sociedade civil e do Estado, sobretudo nos aspectos espaciais, ecológicos, sociais, institucionais e econômicos.

A problemática do modo empresarial de fazer agricultura ganha uma nova conotação em um contexto de crescente globalização e liberalização dos mercados, na medida em que deve produzir em mercados cada vez mais perversos e competitivos, marcados por uma reformulação da produção agrícola à escala global, deterioração dos preços pagos aos produtores e flutuações dos demais preços praticados no mercado (PLOEG, 2008).

Algumas contribuições teóricas da escola institucional

A teoria institucional, enquanto disciplina, ganhou notoriedade com as contribuições de Thorstein Veblen ([1899] 1983), que fundou a primeira abordagem institucionalista, comumente conhecida como a Velha Economia Institucional (VEI). O conceito de instituições, nesta vertente, remete-se ao conjunto de regras, valores e sua própria evolução (CONCEIÇÃO, 2002). A VEI passa por um declínio após a Segunda Guerra Mundial, de modo que, apenas no final da década de 1960, os pressupostos da teoria institucional são retomados, agora sob a égide da abordagem Neo-Institucionalista. Para esta vertente, que sofreu bastante influência teórica da VEI, as instituições configuram duráveis sistemas 
EM

QUESTÃO

V.14 N. $02 \bullet 2021$

pág. 232-261

estabelecidos e regras construídas socialmente que condicionam a interação entre os indivíduos (HODGSON, 2006).

Ainda em meados da década de 1960 e, sobretudo, entre as décadas de 1980 e 1990, uma nova abordagem institucionalista adquiriu destaque. Tratava-se da Nova Economia Institucional (NEI), que define instituições como um conjunto de regras formais (leis, estatutos, códigos legais) e regras informais (cultura, valores morais, crenças) que de alguma forma moldam as relações sociais, políticas e econômicas de uma sociedade (NORTH, 1990).

É no âmbito dessas regras formais e informais, presentes nas suas mais variadas formas em todas as vertentes institucionalistas, que a análise deste trabalho residirá. Em primeiro lugar, do ponto de vista das regras formais, pode-se encontrar, na literatura, importantes estudos que associam "boas instituições" - como a garantia dos direitos de propriedade, um judiciário limpo, uma burocracia eficiente, dentre outras - com o processo de desenvolvimento. Entretanto, Chang (2004) ressalta que essas "instituições boas" só produzirão efeitos sobre a performance econômica dos países se forem acompanhadas das "políticas boas", isto é, aquelas praticadas pelos principais países desenvolvidos e que dizem respeito a idealização de um Estado de bem-estar social.

No que concerne às regras informais, a ideia de capital social emerge como um importante recurso teórico-metodológico para o seu entendimento. Autores como Bourdieu (2007) e Coleman (1988) ressaltam que o capital social apresenta-se como um elemento que dá sustentação, por meio de laços de confiança, reciprocidade, costumes, regras e normas, à coesão e que atua na promoção do bem comum.

Adentrando ainda mais no cerne da questão das instituições informais vis-à-vis capital social, Putnam (1996) apresenta a ideia de comunidade cívica, que teria sido a base fundamental para o bom desempenho das instituições governamentais nas regiões da Itália moderna. Esta comunidade está unida por laços de cooperação e reciprocidade, e não por relações de dependência. As normas e valores da comunidade cívica são reforçados por estruturas e práticas específicas. A análise do autor sobre capital social em relação ao conceito de comunidade cívica remete-se a ideia de que os estoques de confiança, normas e participação tendem a ser acumulados e a se reforçar mutuamente. Dessa forma, são criadas virtudes coletivas que desencadeiam certa equidade social, com elementos de cooperação, reciprocidade, civismo e bem-estar social, que são as principais características que definem a comunidade cívica. 
EM

QUESTÃO

V.14 N. $02 \downarrow 2021$

pág. 232-261

\section{Breves considerações sobre a reforma agrária de mercado}

A RAM configura-se como um modelo neoliberal de reforma agrária, no qual o mercado, e não mais o Estado, passa a ser o principal instrumento de acesso à terra (OLIVEIRA, 2005). Promulgada intelectualmente e financeiramente pelo Banco Mundial, a RAM entrou na agenda da instituição a partir do fim da Guerra Fria, principalmente sob a égide de um conjunto de diretrizes e princípios norteadores para o estudo do desenvolvimento rural e alívio da pobreza (PEREIRA, 2004). Na verdade, a RAM surgiu como uma importante estratégia de legitimação das reformas neoliberais recomendadas pela instituição na década de 1980, sob o argumento de ajuste macroeconômico das economias periféricas.

Nesse contexto, vale ressaltar que a RAM está ancorada em seis princípios básicos (PEREIRA, 2004): (i) transação voluntária entre compradores e vendedores; (ii) enfoque dirigido pela demanda e associativismo; (iii) ideia de que os próprios agentes podem realizar um processo de seleção dos beneficiários; (iv) descentralização, participação e privatização em todas as fases do projeto; (v) esquema flexível de empréstimos e doações; e (vi) estímulo ao desenvolvimento produtivo.

Tratando-se dos aspectos positivos da RAM, Buainain, Silveira e Teófilo (2000) destacam que este modelo é de suma importância para: (i) reduzir a burocracia e as disputas judiciais decorrentes das expropriações; (ii) promover o aumento do número de beneficiários devido à redução de custos, da dependência do setor público federal e de ingerências políticas; e (iii) fomentar um rápido processo de emancipação dos beneficiários.

No que concerne aos aspectos negativos, Pereira (2004) demonstra que o modelo não atingiu os resultados esperados em países como Colômbia, Guatemala, África do Sul e Brasil, especialmente por ter coberto uma porcentagem ínfima daquela população esperada, por ter apresentado burocracia, lentidão e corrupção nos processos de compra e venda de terras, bem como por financiar terras com um valor acima daquele praticado no mercado e muitas vezes de qualidade inferior, reforçando assim o círculo vicioso da pobreza rural.

Corroborando com este pensamento, Sauer (2004) constata: (i) uma grande quantidade de terras de baixa qualidade sendo adquiridas em razão da insuficiência de recursos disponíveis para a compra de terras de melhor qualidade; (ii) um trade-off entre o desejo de comprar terras melhores e os investimentos produtivos, o que limita a expansão da atividade; (iii) não existe evidência empírica de melhora nas condições de vida; e (iv) falta e atraso na liberação de recursos da política. 
EM

QUESTÃO

V.14 N. $02 \bullet 2021$

pág. 232-261

No Brasil, a RAM teve início em 1996, mediante o Programa Reforma Agrária Solidária - Projeto São José, no estado do Ceará. Em 2003, foi instituído o Programa Nacional do Crédito Fundiário (PNCF), contemplando todos os estados das regiões Sul, Sudeste, Centro-Oeste, Nordeste, além dos estados de Tocantins e Rondônia, na região Norte do país. À época do financiamento do Assentamento da Fazenda Paz, o PNCF estabelecia um limite de crédito de até $\mathrm{R} \$ 80.000,00$ para adquirir a terra, com juros de $0,5 \%$ a $2 \%$ e 20 anos para quitar a dívida, sendo três anos de carência.

Atualmente, está em vigor o Terra Brasil - PNCF, englobando todos os estados do país. Outras diferenças que podem ser mencionadas residem no limite do crédito, que passou a ser de até R $\$ 158.358,54$, nos juros, que variam de $0,5 \%$ a $4 \%$, e no prazo de pagamento da dívida, que passou para 25 anos, permanecendo os três anos de carência. Registre-se que desde a institucionalização do PNCF, em 2003, os recursos podem ser utilizados não só para a aquisição do imóvel rural, mas abrangem, também, a infraestrutura necessária da propriedade e estruturação produtiva.

\section{O Assentamento da Fazenda Paz}

A Fazenda Paz Ltda. foi constituída em 2002 e pertencia ao capital estrangeiro, mais precisamente a um empresário alemão, que empreendia ali um projeto de fruticultura irrigada. A produção na empresa era desenvolvida por agricultores assalariados e por outras ocupações não-agrícolas. O projeto da empresa agrícola foi interrompido no ano de 2004 , quando o empresário decidiu parar de investir no Brasil em função da elevação dos custos dos insumos e meios de produção de origem industrial e à queda dos preços dos produtos agropecuários.

O antigo proprietário da Fazenda Paz, ao colocar a propriedade à venda, segundo os relatos de alguns assentados, desejava que a terra fosse adquirida com o intuito de ser desenvolvido um amplo projeto social. Baseando-se nesse fato, no ano de 2007, por intermédio da Secretaria de Estado de Assuntos Fundiários e de Apoio à Reforma Agrária do Rio Grande do Norte (SEARA/RN), os ex-funcionários da Fazenda Paz conheceram o PNCF. O desafio agora se constituía em mobilizar e agrupar trabalhadores para a tomada do crédito do programa.

A mobilização dos trabalhadores coube a um técnico agrícola, antigo funcionário da Fazenda da Paz, onde ocupou uma espécie de gerência de campo. Detentor de muitas informações sobre a Fazenda Paz, tornou-se inicialmente líder do grupo e, posteriormente, 
EM

QUESTÃO

V.14 N. $02 \bullet 2021$

pág. 232-261

presidente da Cooperativa. A diversidade das ocupações dos trabalhadores mobilizados e daqueles selecionados para serem assentados era enorme. Além dos ex-funcionários da Fazenda Paz, existiam pessoas que viviam da pesca no alto mar, arrendatários de terra e trabalhadores da construção civil. Ainda no ano de 2007, cerca de 80 famílias criaram a ACAPAZ e adquiriram a propriedade via recursos do PNCF. Por enfrentar limitações quanto ao mercado e às normas jurídicas, os próprios sócios da ACAPAZ criaram, em 2008, a COOAPAZ.

Tratando-se do modelo de gestão, optou-se por reproduzir a antiga divisão social do trabalho presente na Fazenda Paz. Por um lado, permitiu um maior conhecimento e rapidez no andamento do projeto, dado que os assentados continuaram a desempenhar as mesmas funções. Por outro lado, reforçou a cultura do vínculo empregatício por parte dos assentados, de modo que o sentimento de não empoderamento do negócio prevaleceu.

No topo da gestão tinha-se a diretoria, encarregada, por exemplo, de elaborar, coordenar e executar o plano de trabalho, bem como de criar receitas destinadas a cobrir despesas operacionais e de manutenção. Destaque-se, em seguida, a interligação com os demais departamentos, a saber: (i) financeiro, encarregado de gerir receitas e pagamentos, apresentar a prestação de contas e elaborar os demonstrativos contábeis; (ii) administrativo, incumbido de operacionalizar a gestão de recursos humanos envolvidos no projeto; e (iii) produção e comercialização, o qual coordenava os grupos de produção e atuava na elaboração e implementação da estratégia de comercialização dos produtos.

Cabe destacar o papel dos grupos de produção, que se encontravam na base do modelo de gestão. Segundo o presidente da COOAPAZ, os grupos eram organizados de acordo com aptidão e conhecimento de cada agricultor, possuindo um coordenador em cada grupo. A proposta inicial era desenvolver um programa de agricultura familiar sólido em cerca de 607 hectares de terras, dos quais 120 são irrigados, mediante produção de culturas predominantemente tropicais, em especial, mamão, banana, abacaxi, graviola, limão, coco e melancia. Ainda que o projeto fosse de produção coletiva, ressalte-se que cada assentado foi contemplado com 0,5 hectare visando o desenvolvimento de produções individuais. A ideia era que cada família tivesse autonomia na sua produção, isto é, com liberdade para a venda dos produtos, gerando uma renda extra para os agricultores familiares e fortalecimento da gestão individual.

Em suma, mais do que um plano de agricultura de subsistência, a concepção girava em torno da criação de renda para os agricultores familiares, proporcionando condições para que o desenvolvimento rural fosse alcançado. 
EM

QUESTÃO

V.14 N. $02 \bullet 2021$

pág. 232-261

Com base nesta breve apresentação, é importante destacar que a trajetória do Assentamento apresentou dois momentos distintos. O primeiro, que será analisado no item 5, entre 2007 e 2011, quando o projeto apresentou importantes resultados, tornando-se uma referência na agricultura familiar brasileira. O segundo, que será analisado no item 6 , a partir do ano de 2012, quando os assentados procuraram diversas instituições públicas e federais para que "salvassem" o projeto.

\section{O “bom” na trajetória do assentamento da Fazenda Paz}

O "bom" do período no Assentamento da Fazenda Paz compreende os anos 20072011, caracterizados pela construção da luta pela terra, a obtenção do financiamento, o assentamento das famílias selecionadas, a produção para o autoconsumo, a inserção no mercado local de frutas e hortaliças e, finalmente, a produção em escala para venda nos supermercados locais e no mercado internacional de frutas tropicais, gerando uma remuneração média de $\mathrm{R} \$ 800,00$ a $\mathrm{R} \$ 1.000,00$ por assentado/mês. Diante dessas constatações, busca-se, neste item, compreender os fatores de êxito que propiciaram, no período, um processo de desenvolvimento do projeto, que pode ser creditado à integração de políticas públicas e à existência de diversificação, agentes empreendedores, pluriatividade e capital social.

O papel das políticas públicas na Fazenda Paz

A integração das políticas públicas desempenhou um papel fundamental na formação e no funcionamento da Fazenda Paz. No conjunto das políticas creditícias, o Assentamento teve acesso, além do PNCF, ao Programa Nacional de Fortalecimento da Agricultura Familiar (PRONAF) e ao Programa de Desenvolvimento Solidário (PDS), esse último em âmbito estadual. Em paralelo, os assentados também fizeram parte de outras políticas públicas, principalmente no tocante aos programas que visam à inserção da agricultura familiar no mercado, tais como o Programa de Aquisição de Alimentos (PAA) e o Programa Nacional de Alimentação Escolar (PNAE).

O PNCF apresenta-se como a primeira política pública utilizada pelo Assentamento no ano de 2007. Segundo o presidente da COOAPAZ, cada uma das 80 famílias contratou o 
recurso na ordem de $\mathrm{R} \$ 40.000,00$, totalizando um crédito disponível para a Cooperativa de $\mathrm{R} \$$ 3.200.000,00. Desse valor, aproximadamente $\mathrm{R} \$ 2.560 .000,00(80 \%)$ foram destinados para a aquisição da propriedade e gastos com infraestrutura. Por outro lado, cerca de R\$ $640.000,00$ (20\%) foram designados para o custeio produtivo. Os juros foram de $2 \%$ em 14 parcelas anuais de R \$ 192.000,00, sendo três anos de carência. Segundo informações, estimase que o patrimônio da Fazenda Paz, ao ser adquirida, girava em torno de R \$ 5 milhões, o que teria compensado, portanto, o financiamento via PNCF.

O PRONAF do tipo "A" foi acessado pelos cooperados entre os anos de 2009 e 2010. Neste caso, cerca de 60 famílias contrataram recursos em torno de R $\$ 20.000,00$, totalizando um crédito disponível para o projeto de R \$ 1.200.000,00. Desse total, R \$720.000,00 (60\%) foram alocados na melhoria e ampliação da estrutura física e móvel, principalmente na aquisição de veículos, máquinas e equipamentos. Os outros 40\% ( $\mathrm{R} \$ 480.000,00)$ foram alocados em investimentos produtivos, sobretudo na compra de insumos e contratação de mão de obra externa. Os juros foram de $2 \%$ em 8 parcelas semestrais de $\mathrm{R} \$ 92.000,00$, sendo 1 ano de carência.

No tocante ao PDS, os recursos liberados chegaram ao patamar de R\$97.000,00 no ano de 2010. Inicialmente, foram destinados 50\% desse valor $(48.500,00)$ para reforma da propriedade. A parcela restante $(48.500,00)$ foi alocada na aquisição de equipamentos para a implantação de uma agroindústria de polpa de frutas. Todavia, o presidente da Cooperativa destaca que os recursos do PDS não foram suficientes, o que exigiu uma busca por outros recursos, especialmente o PRONAF Agroindústria. Vale destacar que os recursos do PDS foram a fundo perdido, descartando a obrigação da quitação da dívida por parte dos agricultores familiares

No caso do PAA, os assentados participam do programa desde o ano de 2009. Por meio da modalidade "Compra direta local da agricultura familiar", os produtos da agricultura familiar são comprados a um preço maior que o praticado no mercado. Vale destacar que os valores comercializados pelos agricultores, por meio da COOAPAZ, foram de R $\$ 4.500,00$ por agricultor/ano. De maneira paralela, o PNAE também promoveu a geração de renda para os agricultores familiares da Fazenda Paz. O programa foi acessado no ano de 2011 e possibilitou uma renda permanente para os agricultores. Os valores comercializados foram de $\mathrm{R} \$$ 9.000,00 por agricultor/ano. Considerando-se a possibilidade de que as 80 famílias estivessem participando ativamente do PAA e do PNAE, tem-se um montante anual,

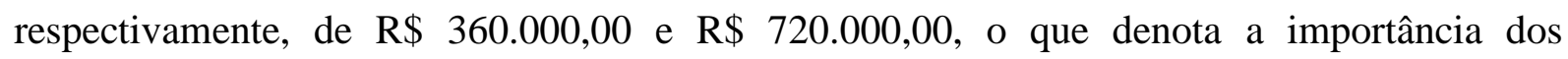
programas para a agricultura familiar. 
EM

QUESTÃO

V.14 N. $02 \bullet 2021$

pág. 232-261

Especificamente no caso do PNAE, informações dos entrevistados convergem para o desenvolvimento satisfatório do programa na região, considerando, ademais, o PNAE como a principal política pública acessada pelos cooperados. Nesse contexto, vale ressaltar que a Fazenda Paz chegou a fornecer seus produtos para 40 escolas no município de Maxaranguape/RN e 20 escolas em Natal/RN.

Observa-se, portanto, que o fortalecimento da agricultura familiar, como defende Veiga, foi um dos elementos propulsores no processo de desenvolvimento rural do Assentamento. Nesse sentido, o crédito fundiário permitiu não só a aquisição da propriedade, mas possibilitou a premissa básica para a subsistência e produção dos agricultores familiares, qual seja, a terra. O crédito rural foi de fundamental importância nesse processo, na medida em que complementou e financiou as condições necessárias para a formação de uma infraestrutura básica e produtiva na Cooperativa. Além destes fatores, a participação em políticas, como no caso do PAA e do PNAE, permitiu a geração de renda direta para os agricultores familiares, elevando a demanda agregada e movimentando a cadeia da circulação econômica na região.

Diversificação, empreendedorismo e pluriatividade

Com base, novamente, nos aspectos teóricos trabalhados por José Eli da Veiga, percebe-se que a diversificação e o empreendedorismo estiveram presentes no caso do Assentamento da Fazenda Paz, contribuindo para o seu desenvolvimento.

Nesse sentido, a combinação da trindade econômica (economias de escala, economias de escopo e custos de transação) com a diversificação produtiva foi outro elemento ativo no período de sucesso do Assentamento. Primeiro, constata-se que a aquisição de máquinas, equipamentos, insumos e a organização dos grupos de trabalho maximizaram a utilidade dos recursos no processo produtivo, reduzindo o custo unitário e gerando significativas economias de escala.

Por sua vez, a homogeneidade do processo produtivo presente nos diferentes cultivos, principalmente devido às matérias-primas utilizadas e a complementariedade do manejo de produção, possibilitou uma elevação dos itens cultivados e da sua respectiva distribuição, gerando economias de escopo para o Assentamento. Por último, a diversificação produtiva possibilitou uma redução dos custos de transação para os agricultores, na medida em que flexibilizou as especificidades dos produtos e proporcionou ganhos de logística. 
EM

QUESTÃO

V.14 N. $02 \bullet 2021$

pág. 232-261

A presença do empreendedorismo, enquanto fenômeno que contribui com a mudança econômica via disseminação de inovações e tecnologias, surgiu como outro motivo básico para o sucesso do projeto. Pode-se retratar como agente representativo desse processo, na Fazenda Paz, o então assentado e presidente da COOAPAZ. Este agente possui formação acadêmica em Técnico Agrícola, o que facilitou a transmissão do conhecimento, das técnicas produtivas e da gestão dos recursos humanos. Da mesma forma, existiam outros cooperados que também conseguiram contribuir com esse movimento a partir de suas capacidades e habilidades, seja na produção ou no âmbito da gestão. Além disso, a permanente busca por instituições externas, principalmente órgãos de assistência técnica privada (Serviço Brasileiro de Apoio às Micro e Pequenas Empresa - Sebrae -, Serviço Nacional de Aprendizagem Industrial - Senai -, Serviço Nacional de Aprendizagem Comercial - Senac), engenheiros agrônomos e técnicos agrícolas, também contribuiu para o processo de disseminação do conhecimento produtivo e organizacional.

Em 2010, uma parceria com o SEBRAE foi firmada no intuito de adequar a produção de mamão para pleitear o Global Gap, selo de qualidade que permite a entrada de produtos no mercado europeu. Com o reconhecimento, os agricultores, mediante parcerias entre a COOAPAZ e empresas que operam no comércio externo do Rio Grande do Norte - as quais atuaram como intermediadoras -, exportaram cerca de 600 toneladas da fruta para Portugal no mesmo ano. Ainda em 2010, adquiriu-se o certificado Fair Trade para abacaxi, limão e coco. O Fair Trade é concedido a produtos que respeitam questões ambientais, sociais e econômicas em todo seu processo. De maneira geral, os certificados atestaram a qualidade das frutas no mercado, possibilitando uma elevação nos preços dos produtos. Essas exportações foram interrompidas pelas consecutivas crises econômicas vivenciadas pela Europa no período.

O caso do Assentamento da Fazenda Paz apresenta outras ligações com os aportes teóricos trabalhados ao longo do estudo. Sendo assim, identificou-se a presença da pluriatividade. De acordo com o presidente da Cooperativa, das 80 famílias, 60 trabalhavam na produção e 20 na administração. Porém, todas as 80 famílias possuíam membros pluriativos. Nesse sentido, de uma família composta por quatro membros, por exemplo, o pai trabalhava no cultivo, a mãe auxiliava a produção, a filha cuidava da parte administrativa e o filho intensificava seus esforços na comercialização dos produtos.

Conclui-se, portanto, que a pluriatividade das famílias do Assentamento da Fazenda Paz canalizou, novamente, esforços para uma produção eficiente do projeto. Por fim, vale destacar que essa divisão social do trabalho da família traduz-se em um fenômeno permanente 
no espaço rural. No caso do Assentamento, as estratégias de alguns membros das famílias, ao diversificarem suas atividades no âmbito interno, contribuiu para uma reprodução social da família.

A ideia de território e o capital social na Fazenda Paz

O período de sucesso do Assentamento da Fazenda Paz também pode ser analisado a partir da ideia de território, enquanto espaço de reprodução da relações sociais, econômicas, institucionais e políticas da agricultura familiar, e do capital social. Guardadas as devidas proporções, o distrito marshalliano se fez presente na Fazenda Paz. Primeiro, um conjunto diversificado de agricultores familiares, isto é, com capacidades e habilidades heterogêneas, sobretudo aqueles com expertise na produção agropecuária, possibilitou a transmissão do conhecimento técnico e produtivo no território.

Segundo, a cooperação apresentou-se como outro fator importante. Ora, sem a cooperação, os beneficiários não teriam se organizado e adquirido a terra. Ademais, o cooperativismo estabelecido permitiu que os produtos fossem comercializados no mercado interno e externo, agregando valor aos produtos da Paz. Por último, a integração entre empresas e indivíduos urbanos e rurais permitiu um intercâmbio de informações e conhecimentos dentro do território. A própria presença de gentes empreendedores, isto é, aqueles capazes de promoverem a mudança econômica, só tiveram êxito na disseminação de inovações face às características do território.

Tratando-se do capital social, observa-se que o Assentamento da Fazenda Paz possuiu um capital social ativo, ainda que isto tenha ocorrido, fundamentalmente, no início do projeto. A partir de relatos, sugere-se que sua constituição se deu a partir de histórias em comum, na esperança de ascensão social e econômica, gerando uma confiança e reciprocidade entre os beneficiários. Esse processo foi retroalimentado pelos próprios resultados iniciais, que se mostravam satisfatórios. Não se pode deixar de considerar o papel das ações - ainda que possa avaliá-las, sobretudo em uma perspectiva de longo prazo - de capacitação e sensibilização, por vezes capitaneadas por instituições externas e o próprio Estado.

Logicamente, a não existência desse capital social ativo dificultaria o alcance dos objetivos propostos pelo projeto. Nesse sentido, conforme relatos, a confiança no trabalho coletivo, no conhecimento do próximo e nas ações realizadas atuou de suma importância para a implantação do projeto. Ademais, a crença de que todos pagariam a dívida contratada permitiu a tomada de crédito via PNCF e PRONAF. 
EM

QUESTÃO

V.14 N. $02 \bullet 2021$

pág. 232-261

\section{O "mau" e o "feio" na história do assentamento da Fazenda Paz}

O conjunto dos fatores enunciados no item 5 contribuiu para o período de maior êxito do Assentamento. Esse momento durou até o final de 2011, quando passou a enfrentar sérios problemas, culminando, até então, na descontinuidade do projeto coletivo e desativação da COOAPAZ. No período da pesquisa de campo, verificou-se que apenas a ACAPAZ permanecia formalmente constituída.

No ano de 2012, os assentados da Fazenda Paz procuraram diversas instituições públicas e federais para que o projeto recebesse uma maior atenção. Segundo os relatos, a receita do empreendimento não conseguia mais cobrir os custos de produção e o pagamento dos financiamentos contraídos. De caráter ainda mais importante, problemas internos pareciam desmotivar e desacreditar o grupo de 80 famílias que adquiriu a terra. É neste cenário conflituoso que a análise deste item residirá. Busca-se, portanto, entender e identificar explicações para o declínio da trajetória do Assentamento da Fazenda Paz.

A ótica dos assentados

No processo de venda da Fazenda Paz, um dos Associados entrevistados lembra que promoveu-se uma seleção de potenciais beneficiários, dando-se prioridade aos exfuncionários. Os demais interessados proviam de diferentes origens e ocupações não propriamente ligadas ao setor agrícola. Percebem-se, aqui, dois problemas iniciais. O primeiro consistia na cultura do assalariamento do próprio agricultor. Ora, os ex-funcionários estavam acostumados a receberem uma quantia em dinheiro por dia trabalhado. Existia, portanto, uma regra formal que coordenava e movia os trabalhadores para um determinado fim. Vale destacar que em uma das primeiras assembleias após a compra da propriedade, os assentados decidiram continuar recebendo por dia trabalhado. Segundo o Associado, cada agricultor chegou a receber uma diária $\mathrm{R} \$ 25,00$. Em segundo lugar, o grande contingente de famílias reunidas na Fazenda Paz remete-se à diversidade de cultura, costumes, crenças, enfim, uma série de instituições informais que passariam a existir na propriedade.

Segundo relatos, existia uma clara separação entre a diretoria e os associados, de modo que a diretoria administrava a Fazenda Paz como se fossem os únicos proprietários. Por sua vez, os demais assentados possuíam valores culturais e crenças impregnadas que reforçavam o sentimento de empregados da diretoria. Na prática, transplantou-se a antiga divisão social 
do trabalho na propriedade, isto é, manteve-se a gerência, no papel da diretoria, e os trabalhadores, formalizados pelas diárias, no papel dos assentados.

Obviamente, essa regra da diária iria se sustentar enquanto houvesse receita para pagar os agricultores. Um dos entrevistados lembra que, no início, o mercado nunca foi problema para o projeto. Além dos grandes supermercados de Natal, os Frutos da Paz chegaram a ser exportados para Fortaleza, Portugal e Espanha. A venda ocorria acima do preço de mercado, o que gerava uma receita alta e que custeava as diárias. Entretanto, a diretoria da COOAPAZ, que realizava o pagamento das diárias, começou a incorrer em prejuízos e problemas com a comercialização. Com isso, a receita obtida não conseguia mais cobrir as diárias, motivando a desconfiança dos agricultores. O desejo dos agricultores passava, então, por uma prestação de contas do grupo gestor. Na verdade, a prestação de contas, que estava prevista no estatuto da ACAPAZ, nunca foi realizada. Existia, portanto, uma falta de transparência na gestão que fomentava a desconfiança dos demais assentados.

A desconfiança dos agricultores contra a diretoria fez florescer outras indagações das regras que existiam no funcionamento da Fazenda. Retomando-se o papel da diária, um dos beneficiados entrevistados afirma que a diretoria recebia uma diária maior que o valor pago aos agricultores - não foi possível, durante a pesquisa de campo, identificar essas possíveis diferenças e valores. A justificativa, dada pelos próprios diretores ao Associado, era que o grupo gestor trabalhava mais horas que os demais agricultores. Por sua vez, os associados reclamam, novamente, da falta de transparência para uma maior comprovação deste fato. Claramente, aquele capital social construído no início da Fazenda Paz foi se rompendo, culminando na perda de credibilidade da diretoria perante os associados.

Diante desse cenário já conflituoso, a falta de transparência também motivou a paralização do ambiente produtivo. Segundo uma liderança, criaram-se os grupos de produção e comercialização. Os associados, que faziam parte do grupo de produção, entregavam as frutas para COOAPAZ, que contemplava o grupo de comercialização. O grande problema é que os recursos com a venda dos produtos não estavam sendo repassados para a ACAPAZ, inviabilizando o reinvestimento necessário no ambiente produtivo. Pelo lado da COOAPAZ, o então presidente afirmava que os recursos estavam sendo repassados. Por sua vez, o presidente da ACAPAZ afirmava justamente o contrário. Todo esse ambiente de incertezas e a consequente paralização do grupo de produção fizeram com que a COOAPAZ, para não perder mercado, buscasse produtos em outras regiões. De forma geral, críticas foram realizadas acerca da falta de apoio do Estado nesse processo. Seguindo a lógica da RAM, o Estado delega a gestão e as demais funções inerentes à propriedade aos beneficiários. 
EM

Entretanto, os relatos aludem sobre o fato de que o Estado poderia participar mais do processo, fiscalizando e cobrando uma maior transparência da gestão da diretoria.

Uma outra liderança entrevistada chama atenção para a não prestação de contas. Segundo destaca, boa parte dos associados não se atentava para esse fato, mas a regra formal prevista no estatuto não estava sendo cumprida. Por sua vez, vale ressaltar que muitos dos agricultores não exigiam uma maior transparência da gestão.

Outro problema destacado era a questão do valor recebido pelo dia trabalhado, a chamada diária. Na sua ótica, a institucionalização dessa regra partiu da própria diretoria, que detinha grande respeito perante os associados. Na verdade, os agricultores, até por falta de conhecimento, acreditavam que essa era melhor forma de trabalho. Nesse contexto, os relatos apontam que a cultura do agricultor e o seu sistema de crenças favoreciam essa prática, na medida em que os agricultores confiavam suas ações em um único departamento da Fazenda Paz.

De fato, os resultados satisfatórios da Fazenda Paz legitimavam as ações da diretoria, de modo que os demais assentados possuíam uma regra informal internalizada de que o modelo estava sendo executado da forma correta. Entretanto, no ano de 2012, a diretoria passou a apresentar alguns resultados negativos do projeto, utilizando esse fato para deixar de cumprir com suas obrigações com os associados. Novamente, a questão da prestação de contas voltava a ser cobrada pelas famílias, que não tinham a clara informação dos demonstrativos contábeis da propriedade. A desconfiança passou a imperar nas atividades, interferindo decisivamente na continuidade das ações produtivas e nas relações sociais entre os indivíduos.

Frise-se, novamente, críticas no que tange ao papel do Estado no âmbito interno da propriedade. Para uma Associada, a Fazenda Paz clamava por uma intervenção e fiscalização maior do Estado no andamento das ações. Além desses problemas, a entrevistada destaca que a Fazenda Paz recebeu um financiamento para a construção de casas para as famílias assentadas. Em uma determinada assembleia, os associados acordaram que tal recurso seria destinado para produção de mamão, principal produto comercializado pela propriedade. De acordo com os relatos, o mamão não apresentou os resultados esperados, incorrendo em custos crescentes com a produção. A diretoria alegou que a fruta sofreu com doenças, argumento este refutado por uma liderança entrevistada. 
EM

QUESTÃO

pág. 232-261

Os argumentos da diretoria

Visando-se ter um contraponto com as opiniões acima apresentadas, optou-se por entrevistar representantes da atual diretoria. Nesta perspectiva, desde a sua formação, o Assentamento da Fazenda Paz não detinha um quadro ativo, isto é, muitas pessoas desistiram do projeto ainda na primeira semana de funcionamento, o que forçava a busca por outros beneficiários. Esse fato atrasava o andamento do projeto, dado que novas capacitações e períodos de experiência deveriam ser realizados com os beneficiários ingressantes. $\mathrm{Na}$ verdade, não existiam regras que coagissem essa desistência, permitindo assim a livre entrada e saída dos beneficiários.

Outro problema levantado foi a falta de participação dos demais membros. Informações demonstram, por exemplo, que boa parte dos associados não se engajava nas discussões, nas reuniões e nas atividades administrativas da Fazenda Paz. Em outras palavras, os assentados delegavam as várias funções gerenciais existentes a um grupo específico. A reduzida participação também se refletia nas eleições para a diretoria, marcadas sempre pela existência de uma chapa única.

É neste contexto que as regras informais voltam a emergir. Ora, a reduzida participação e a não discussão dos aspectos inerentes ao projeto eram características da própria cultura dos agricultores, que preferiam centrar suas atenções e seus esforços na produção. $\mathrm{O}$ costume de não participar ativamente do projeto e a crença nas ações da diretoria configuraram regras ineficientes e limitaram o desenvolvimento do projeto no período.

Essa distância, por parte da maioria dos assentados, dos acontecimentos da Fazenda Paz também se refletiu na tão criticada prestação de contas. Segundo a diretoria, enquanto os resultados eram satisfatórios, os associados nunca cobraram a prestação de contas. Entretanto, com a crise de 2012, a prestação de contas passou a ser cobrada com mais veemência. A diretoria afirma que não enxerga problemas para a realização da prestação de contas, mas entende que este processo deve ocorrer com uma maior participação dos associados e, não somente, delegar esta função a um grupo específico.

Retomando-se a regra da diária paga ao trabalhador, a diretoria admite que esse foi um dos grandes problemas da gestão do projeto. Por sua vez, ressalta que essa preferência pela diária foi decidida pelos próprios associados. Neste caso, críticas convergem para a mentalidade do próprio agricultor em se sentir ainda funcionário e não proprietário do Assentamento da Fazenda Paz. 
EM

Conforme destacou-se anteriormente, houve um momento em que a diretoria não teve mais condições de efetuar o pagamento das diárias. A receita dos Frutos da Paz, segundo informações, foi prejudicada pela existência de uma regra formal de comercialização com um dos grandes supermercados de Natal, na qual a Fazenda Paz deveria arcar com as despesas de avaria dos produtos, além de efetuar o pagamento de um promotor para monitorar as vendas. Ao final, o lucro com a comercialização dos produtos ficou reduzido e as despesas com os investimentos realizados, produção e diárias cresciam consideravelmente. Do ponto de vista dos demais assentados, o grau de confiabilidade nesse argumento é baixo em virtude da falta de transparência da gestão.

A ausência de assistência técnica e da atuação do Estado, em uma perspectiva ampla, na Fazenda Paz também consistiu em um importante apontamento realizado pela diretoria. As lideranças entrevistadas creditam, ademais, as falhas do modelo de gestão à inexperiência dos assentados, especialmente aqueles que faziam parte da diretoria, em coordenarem um projeto de tamanha dimensão. Aqui, vale mais uma crítica ao princípio de auto-gestão do modelo imposto pela RAM. Ora, muitos dos assentados nunca tiveram contato com a esfera fiscal, tributária, jurídica, de modo que delegar recursos e funções, sem o devido apoio técnico, é entregá-los à própria sorte.

Após investigar os problemas vivenciados pela Fazenda Paz a partir dos relatos dos assentados e da diretoria, torna-se importante analisar a opinião de pessoas vinculadas às instituições que conheceram o projeto e, sobretudo, desempenharam algum papel no Assentamento. A seguir, serão discutidas as visões de representantes da FETARN, MDA, EMATER/RN e da OASIS.

\section{As opiniões das instituições externas}

Tratando-se da visão dos representantes da FETARN, um dos primeiros problemas destacados refere-se a origem dos assentados que foram compor o projeto, historicamente acostumados a receberem salários, algo que não condizia com a proposta do projeto coletivo. Ademais, boa parte dos beneficiários não detinha o espírito e a vontade de se tornar proprietários do negócio, o que também dificultava o desenvolvimento do projeto.

Conforme destacam os representantes da FETARN, as reuniões e capacitações iniciais realizadas com o grupo mostravam-se problemáticas. Na verdade, tais ações eram marcadas pela passividade dos agricultores. Nesse sentido, os entrevistados entendem que o grupo 
EM

QUESTÃO

V.14 N. $02 \bullet 2021$

pág. 232-261

formado pela diretoria centralizou as ações, reforçando a não participação dos demais associados.

Retomando-se a questão do assalariamento, está claro que a continuidade dessa cultura foi um grave problema existente na Fazenda Paz. Entretanto, uma informação nova, fornecida pelos representantes da FETARN, demonstra que a origem do recurso para o pagamento da diária foi equivocada. $\mathrm{Na}$ verdade, o recurso era proveniente do financiamento das políticas públicas e não da comercialização dos Frutos da Paz. Enquanto o crédito era abundante, as diárias estavam sendo pagas, mas, quando o financiamento esgotou-se, o projeto não conseguiu assumir os compromissos utilizando apenas a receita originária da terra.

Conforme destacou-se anteriormente, o desenrolar desse processo culminou com a ruptura de confiança por parte dos assentados, que não entendiam como a diretoria apresentava resultados positivos do projeto e, posteriormente, incorria em dívidas e não conseguia cumprir seus compromissos. Na concepção dos entrevistados, a diretoria, até por incapacidade técnica e falta de conhecimento, apresentava resultados que não condiziam com a realidade.

A receita proveniente da terra foi bastante comprometida pelos prejuízos auferidos com a produção de mamão, mercado bastante visado pelo Assentamento. Os representantes da FETARN explicam que esta fruta exige um alto grau de planejamento e tecnologia utilizada, além de um cuidado especial permanente, o que aumenta o custo final de produção. Por outro lado, sua lucratividade pode ser bastante elevada, dependendo das condições do mercado. $\mathrm{O}$ problema, segundo os entrevistados, é que o mamão não gerou os resultados esperados na Fazenda Paz, principalmente em razão de pragas e pela baixa do preço praticado no mercado vis-à-vis redução da demanda pelo produto. Somado a esses fatores, ocorreu a falência de uma das principais empresas compradoras do mamão da Fazenda Paz.

Outro ponto importante destacado pelos entrevistados é que, enquanto o grupo da diretoria possuía a ideia de uma produção em larga escala, com o uso intensivo de tecnologia e voltada para a comercialização interna e externa, a maioria dos assentados estava interessada em garantir a sua subsistência e de suas famílias. Por mais que a gestão tenha sido complicada, os representantes da FETARN destacam que houve um problema precedente, que consistiu na falta de assistência técnica, tanto para lidar com culturas que exigiam um alto grau de especialização, como o mamão, quanto para cultivar os aspectos associativistas e gerenciais do projeto.

No que concerne à opinião do MDA, recomenda-se que um projeto financiado pelo PNCF contemple, no máximo, 20 famílias. Partindo desta observação, o entrevistado salienta 
EM

QUESTÃO

V.14 N. $02 \bullet 2021$

pág. 232-261

que, dada a dimensão do projeto e o elevado número de famílias envolvidas, o Assentamento da Fazenda Paz sempre mereceu uma atenção especial.

Tratando-se dos aspectos de gestão, o membro do MDA observa que os assentados da Fazenda Paz compraram um modelo empresarial e decidiram dar continuidade à divisão social do trabalho. Esse processo apresentou dois lados. Em um primeiro momento, o projeto exibiu bons resultados por duas razões, são elas: (i) potencial da propriedade, que abrangia toda uma infraestrutura produtiva previamente implantada pelo antigo proprietário; e (ii) a maioria dos beneficiários já conhecia a propriedade, dado que eram ex-funcionários da Fazenda Paz, o que facilitou o andamento do projeto. Ademais, as políticas de comercialização foram de suma importância para a inserção dos assentados no mercado e para a geração de renda.

Em um segundo momento, essa continuidade gerou um problema e reforçou outro. Por um lado, gerou-se um problema ao tentar transpor um modelo empresarial, caracterizado pelo alto grau de tecnologia e insumos avançados, para a mentalidade de agricultores familiares acostumados com suas técnicas rudimentares. Por outro lado, reforçou-se um problema ao manter a mesma divisão do trabalho, isto é, uma espécie de gestor geral do projeto e os demais "empregados", que continuavam a desempenhar funções designadas pela diretoria e a receberem diária pela atividade realizada, permanecendo assim com a cultura do vínculo empregatício.

Outro problema levantado pelo representante refere-se à moradia dos assentados. A Fazenda Paz servia, principalmente, como ambiente produtivo para os assentados. Na verdade, a propriedade abrigava poucas casas, de modo que muitos associados não residiam na Fazenda. Por sua vez, os que se aventuravam em residir na propriedade, deveriam compartilhar a mesma residência com três ou quatro famílias. Esse cenário poderia ser mudado, mas optou-se por destinar o financiamento previsto para a construção das habitações rurais para o ambiente produtivo, especialmente para a produção do mamão. É nesse ponto que reside a crítica do representante do MDA, argumentando que é muito mais interessante o assentado residir na sua propriedade, permitindo assim um maior grau de pertencimento ao local e o estreitamento das relações entre os indivíduos.

Do ponto de vista produtivo, o representante do MDA chama atenção para o foco excessivo na fruticultura irrigada. Na sua visão, a Fazenda Paz possui uma estrutura capaz de abranger a pecuária, com base nas atividades leiteiras e na produção de sorgo, milho e capim. Esse potencial produtivo da propriedade nunca foi explorado, muito em razão das características e dos conhecimentos dos assentados. 
EM

Além dessa crítica, o entrevistado tece importantes comentários sobre o modo de produção utilizado pela Fazenda Paz. Na sua visão, optou-se por um modelo de forte dependência dos insumos químicos produzidos pela indústria, tais como adubos, fertilizantes e venenos, elevando as despesas com a produção. Nesse caso, os altos investimentos realizados necessitavam de um mercado consumidor que sustentasse o projeto, algo que não ocorreu com a Fazenda Paz.

O grande problema é que o sistema financeiro possui regras que reforçam a dependência dos agricultores familiares em relação à indústria. Segundo o entrevistado, caso os agricultores queiram contratar um financiamento para produzir mamão, por exemplo, a instituição financeira aprovará apenas os projetos que contemplem o intensivo uso de insumos químicos. Ao criar barreiras institucionais que impedem a autonomia do pequeno produtor, o sistema financeiro fortalece sua relação com as grandes empresas, gerando um processo de aprofundamento do capital e do progresso técnico na agricultura.

O representante também critica a falta de assistência técnica. Dada a dimensão do projeto, entende que a Fazenda Paz careceu de uma assistência técnica que se fizesse presente diariamente e nos mais variados aspectos, desde o setor agrícola, passando pelo social até a gestão. A ausência do Estado também é lembrada pelo entrevistado, que critica o afastamento de alguns órgãos diante dos problemas vivenciados pela Fazenda Paz.

No que tange à visão da EMATER, o representante relata que sempre teve desconfiança em um projeto daquela dimensão ser administrado por um grupo de trabalhadores rurais sem o devido preparo e experiência técnica. Diante dessa desconfiança, tornava-se de suma importância um trabalho de base com o grupo. De fato, iniciou-se um processo de discussões, reuniões e cursos para a capacitação do grupo. Entretanto, o entrevistado destaca que uma parte dos assentados conseguia apreender e retirar proveito daquele trabalho, enquanto os demais sentiam dificuldades na absorção das informações. Em que pese essa heterogeneidade, a existência de alguns assentados empreendedores fez com que as instituições externas passassem a acreditar no projeto.

O representante da EMATER lembra que, na época, a Fazenda Paz enfrentou problemas na produção dos seus principais produtos, isto é, mamão e abacaxi, comprometendo a receita. Por um lado, considera que o mamão não foi bem tratado tecnicamente, resultando em prejuízos com a sua produção. Por outro lado, entende que o solo da Fazenda Paz é impróprio para a produção de abacaxi, o que exigia cada vez mais a utilização de insumos, principalmente oriundos da indústria. 
EM

O entrevistado concentra sua crítica no modelo de produção idealizado pelo projeto da Fazenda Paz. Nesse contexto, ressalta que cada agricultor familiar possui sua aptidão, seus esquemas cognitivos, sua cultura de produção, devendo-se respeitar estas características. $\mathrm{Na}$ verdade, organizou-se uma estrutura, transplantou-se um modelo e não levou-se em conta as dificuldades de adaptação dos assentados. No que diz respeito à assistência técnica, o entrevistado entende que não houve ausência, tanto é que diversas instituições, como SEBRAE, MDA, SEARA e UFRN, por exemplo, realizaram serviços com os assentados. A sua hipótese é que a assistência foi realizada de forma equivocada, isto é, não foi capaz de preparar e atender o grupo de acordo com suas necessidades.

Por último, tratando-se da entrevista com o membro da Incubadora OASIS, ressalta-se que os problemas levantados convergiram com aqueles apontados pelos demais entrevistados. A OASIS entrou na Fazenda Paz já no período crítico e criou a chamada árvore dos problemas, procurando elencar os principais fatores que estavam dificultando o desenvolvimento do projeto. Os resultados encontrados detectaram que a não prestação de contas constituía-se o principal entrave no Assentamento da Fazenda Paz, desencadeando toda a desconfiança entre os agentes e a consequente descontinuidade.

Nesses termos, o membro do OASIS observa que os assentados não possuíam um claro entendimento do que viria a ser uma prestação de contas, evidenciando não somente a falta de conhecimento, como também o despreparo em participar de um projeto daquela dimensão. Dessa forma, critica-se, mais uma vez, o afastamento do Estado diante dos problemas gerenciais presentes na propriedade. Após a investigação dos problemas, a OASIS chegou à conclusão de que a solução passava pela realização de uma prestação de contas e retomada da credibilidade do grupo gestor. Para tanto, os associados decidiram eleger uma nova diretoria, mas novos problemas institucionais bloqueavam o desenvolvimento do projeto. Após algumas gestões, a primeira diretoria retomou a administração do projeto.

O resultado de todo esse processo é que, até o momento da pesquisa de campo, só existe a ACAPAZ. A COOAPAZ foi desativada em um cenário de dívidas e descrédito. Para a retomada das atividades da COOAPAZ, a atual diretoria estima que incorrerá em um gasto de $\mathrm{R} \$ 150.000,00$ para o pagamento das dívidas e regularização das questões burocráticas. A principal fonte de renda dos agricultores que ali permaneceram é o quintal produtivo, projeto interno criado ainda no início, no qual cada assentado tem direito a cerca de 0,5 hectare para que desenvolvam produções individuais e exerçam a autogestão. A perspectiva era que ocorresse a individualização dos lotes da Fazenda Paz, de modo que cada agricultor receberia seu pedaço de terra, além do quintal produtivo, individualizando a produção e a dívida com a 
EM

QUESTÃO

V.14 N. $02 \bullet 2021$

pág. 232-261

terra. Destaque-se que não foi possível identificar o andamento do pagamento dos financiamentos, em especial aquele junto ao PNCF. De todo modo, a individualização da dívida foi assinalada por todos os entrevistados como a melhor alternativa para o Assentamento da Fazenda Paz.

\section{Reflexões finais}

De posse do que foi apresentado, algumas importantes reflexões podem ser abstraídas. Em primeiro lugar, concordando-se com a perspectiva adotada por Sabourin (2008), admitese que a disjuntiva reforma agrária por interesse social versus RAM constitui um falso debate, especialmente em função da terra ser uma mercadoria nas duas formas. O que difere, na verdade, esses modelos é a estratégia de gestão dos assentamentos, sendo que, no primeiro, a gestão cabe ao governo federal, por meio do Instituto Nacional de Colonização e Reforma Agrária (INCRA), enquanto no segundo, a gestão é realizada pelas associações civis formalmente constituídas.

Em segundo lugar, o modo de fazer agricultura empreendido pelo projeto da Fazenda Paz privilegiou um modelo empresarial, baseado em uma produção de larga escala, com intensivo uso em tecnologia e fortemente dependente do mercado. Dessa forma, os assentados se distanciaram da coprodução com a natureza viva e passaram a depender dos insumos industriais para criarem sua própria base de recursos, incorrendo assim em crescentes custos de produção e estabelecendo relações sociais essencialmente mercantis.

Como em qualquer modelo empresarial agrícola, a produção é orientada para o mercado. Por sua vez, o mercado, como uma mão invisível, deve proporcionar as condições necessárias para a reprodução capitalista, principalmente no que concerne à estabilidade dos preços e a garantia de uma margem positiva dos preços pagos aos produtores em relação aos seus custos. Caso o mercado não tenha a capacidade de garantir a perfeita harmonia da reprodução do modo empresarial de fazer agricultura - como parece ser a situação normal - o Estado deve intervir no processo. No caso do Assentamento da Fazenda Paz, nem o mercado foi capaz de garantir a sustentabilidade da produção tampouco o Estado interveio nessa situação crítica.

Conforme destaca Ploeg (2008), em um contexto cada vez mais de globalização e liberalização dos mercados, o modo empresarial de agricultura apresenta importantes limites. Some-se a esse contexto o modelo de gestão conduzido por agentes, seja de qualquer natureza 
ou dimensão, desprovidos de capacitação administrativa e financeira para atuarem em um ambiente econômico tão perverso. O caso da Fazenda Paz é mais um que se repete no meio rural brasileiro, em especial, no Rio Grande do Norte, onde a crença no modelo empresarial está enraizada nos mais diversos segmentos e vem determinando o insucesso de arranjos produtivos.

Aliás, a crença no modelo moderno merece uma terceira reflexão importante. Ora, são as crenças, os costumes, os valores, a cultura, em suma, é o conjunto de regras informais, impregnadas na sociedade e na economia, que fundamenta a escolha de um padrão técnico de produção em detrimento de outro. Aproximando esta discussão do caso da Fazenda Paz, pode-se concluir que os assentados optaram por transplantar o modelo pré-existente porque acreditavam que essa era forma mais rentável, porque entendiam que o aumento da produção em escala só seria possível pelo uso intensivo de máquinas, equipamentos e insumos industriais, porque confiavam na reprodução da antiga divisão social do trabalho existente na propriedade e, finalmente, porque detinham a cultura do assalariamento. De fato, essas instituições estavam fortemente enraizadas na Fazenda Paz, tanto é que os assentados não se atentaram para o fato de que o modelo empresarial ali empreendido já apresentava problemas com o antigo proprietário.

Em quarto lugar, a RAM precisa ser revista. Descentralizar as ações e permitir que os agricultores familiares sejam os gestores do projeto, isto é, que negociem o preço da terra, realizem os investimentos, decidam como fazer, como produzir, quem irá participar, enfim, é concordar em entregá-los a um ambiente competitivo e hostil regido pelas leis de mercado. É neste contexto que o papel do Estado e de uma rede de assistência técnica se faz necessário. Por fim, antes de conceber um projeto coletivo de grandes proporções, como o Assentamento da Fazenda Paz, o Estado deve levar em contar, por exemplo, as potenciais características heterogêneas dos beneficiários e o nível de capital social envolvido, de modo que se possa analisar e avaliar os possíveis impactos com a implantação do projeto. Dessa forma, acreditase que os projetos coletivos podem se tornar viáveis desde que o Estado também participe do projeto por meio de um intenso trabalho de base, bem como monitorando e avaliando as ações dos indivíduos.

Apreende-se, portanto, que o desenvolvimento rural é um fenômeno pautado na interação entre boas políticas e um ambiente institucional favorável. Nesse contexto, corrobora-se com a ideia de Veiga et al. (2001) sobre a criação de um Contrato Territorial de Desenvolvimento (CTD), isto é, uma estratégia multidimensional e de responsabilidade mútua, envolvendo não somente a produção, a organização e a comercialização, mas que 
fortaleça as relações e as sinergias entre os arranjos de agricultores familiares. Ademais, devese incentivar um modelo de produção que preze pelos recursos naturais, reduzindo assim a dependência dos insumos industriais.

\section{Referências}

ABRAMOVAY, Ricardo. O capital social dos territórios: repensando o desenvolvimento rural. Revista de Economia Aplicada, São Paulo, v. 4, n. 2, p. 379-397, abr-jun. 2000.

ABRAMOVAY, Ricardo; BEDUSCHI FILHO, Luiz Carlos. Desafios para o desenvolvimento das regiões rurais. Revista Nova Economia, Belo Horizonte, v. 14, n. 3, p. 35-70, set-dez. 2004.

BOURDIEU, Pierre Félix. O Poder Simbólico. Tradução de Fernando Tomaz. 11. ed. Rio de Janeiro: Bettrand Brasil, 2007.

BUAINAIN, Antônio Márcio; SILVEIRA, José Maria da; TEÓFILO, Edson. O programa Cédula da Terra no contexto das novas políticas de reforma agrária, desenvolvimento e participação: uma discussão das transformações necessárias e possíveis. In: Pedro Sisnando Leite et al. (Orgs.) Reforma agrária e desenvolvimento sustentável. Brasília: MDA/NEAD, 2000. p. 157-174.

CHANG, Ha-Joon. Chutando a escada: a estratégia do desenvolvimento em perspectiva histórica. São Paulo: Unesp, 2004.

COLEMAN, James Samuel. Social capital in the creation of.human capital. American Jornal of. Sociology, University of Chicago Press, Chicago, v. 94, Suplement, p. 95-120. 1988.

CONCEIÇÃO, Octavio Augusto Camargo. O conceito de instituição nas modernas abordagens institucionalistas. Revista Economia Contemporânea, Rio de Janeiro, v. 6, n. 2, p. 119-146, jul-dez. 2002.

HODGSON, Geoffrey Martin. What Are Institutions? Journal of Economic Issues, v. XL, n. 1, march. 2006.

NORTH, Douglass Cecil. Institutions, institutional change and economic performance. Cambridge: Cambridge University Press, 1990.

PLOEG, Jan Douwe Van Der. Camponeses e impérios alimentares: lutas por autonomia e sustentabilidade na era da globalização. Trad. Rita Pereira. Porto Alegre: UFRGS, 2008.

PUTNAM, Robert David. Comunidade e Democracia: a experiência da Itália moderna. Rio de Janeiro: Fundação Getúlio Vargas, 1996. 
EM

OLIVEIRA, Alexandra Maria de. A contra-reforma agrária do banco mundial e os camponeses no Ceará. 2005. 379 p. Tese (Doutorado em Geografia Humana) - Faculdade de Filosofia, Letras e Ciências Humanas, Universidade de São Paulo, São Paulo, 2005.

PEREIRA, João Márcio Mendes. O modelo de reforma agrária de mercado do Banco Mundial em questão: o debate internacional e o caso brasileiro. Teoria, luta política e balanço de resultados. 2004. 282 p. Dissertação (Mestrado em Ciências) - Curso de Pósgraduação em Desenvolvimento, Agricultura e Sociedade, Universidade Federal Rural do Rio de Janeiro, Rio de Janeiro, 2004.

SABOURIN, Eric Pierre. Reforma agrária no Brasil: considerações sobre os debates atuais. Revista Estudos sociedade e agricultura, Rio de Janeiro, v. 16, n. 2, p. 151-184. 2008.

SAUER, Sérgio. A terra por uma cédula: estudo sobre a "reforma agrária de mercado". In: Mônica Martins (Org.) O Banco Mundial e a terra: ofensiva e resistência na América Latina, Ásia e África. São Paulo, Viramundo, 2004.

SCHNEIDER, Sérgio. A pluriatividade e o desenvolvimento rural brasileiro. Cadernos do CEAM, Brasília, v. 5, n. 17, p. 23-42. 2005.

SCHNEIDER, Sérgio. A pluriatividade na agricultura familiar. 2. ed. Porto Alegre: Editora da UFRGS, 2009.

SOUZA, Raquel Pereira; SOUZA, Marcelo Santos. O debate brasileiro sobre a pluriatividade: implicações sobre o desenvolvimento rural e as políticas públicas. In: XLVI CONGRESSO DA SOCIEDADE BRASILEIRA DE ECONOMIA, ADMINISTRAÇÃO E SOCIOLOGIA RURAL, 2008, Rio Branco. Anais do XLVI Congresso da Sociedade Brasileira de Economia, Administração e Sociologia Rural. Rio Branco, 1998. p. 1-21.

VEBLEN, Thorstein Bunde. [1899]. A teoria da classe ociosa: um estudo econômico das instituições. São Paulo: Abril Cultural, 1983.

VEIGA, José Eli da. Desenvolvimento rural: o Brasil precisa de um projeto. In: XXXVI CONGRESSO BRASILEIRO DE ECONOMIA, ADMINISTRAÇÃO E SOCIOLOGIA RURAL, 1998, Poços de Caldas. Anais do XXXVI Congresso Brasileiro de Economia, Administração e Sociologia Rural. Poços de Caldas, 1998. p.153-186.

VEIGA, José Eli da. O Brasil rural ainda não encontrou seu eixo de desenvolvimento. Revista Estudos Avançados, São Paulo, v. 15, n. 43, p. 101-119. 2001.

VEIGA, José Eli da et al. O Brasil rural precisa de uma estratégia de desenvolvimento. Série textos para discussão, n. 1. Brasília: MDA/NEAD, 2001. 